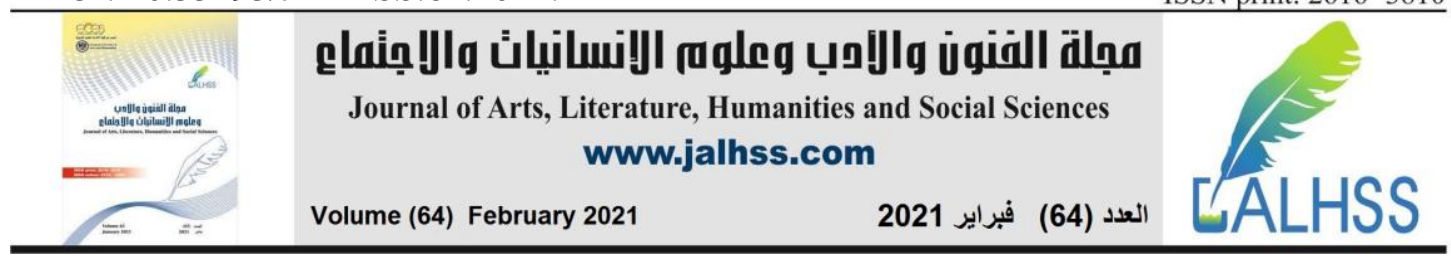

\title{
The Evolution of Plastic Art Implementations in Interior Design (Comparative Study)
}

\author{
Mohammad Ahmad Bani Salameh \\ Luminus Technical University College, 11118 Amman, Jordan \\ Email: msalammeh@yahoo.com
}

\begin{abstract}
This study will discuss the evolution of artworks implementations in interior design, as there was a significant change in these artworks used in interior design that adopts a classic style from the other one used a contemporary design.

This study has compared (4) interior design cases (study sample) of classical and contemporary design models, in each case two designs were compared of classical and contemporary design, and both have one form of art, to prove the evolution of plastic art elements with interior design in parallel The results have shown that there are a significant evolution in art elements implemented in interior design and that prove clearly the implication of interior design on art elements in case both are being together.
\end{abstract}

Keywords: Interior Design, Plastic Art, Comparative Analysis, Arts. 


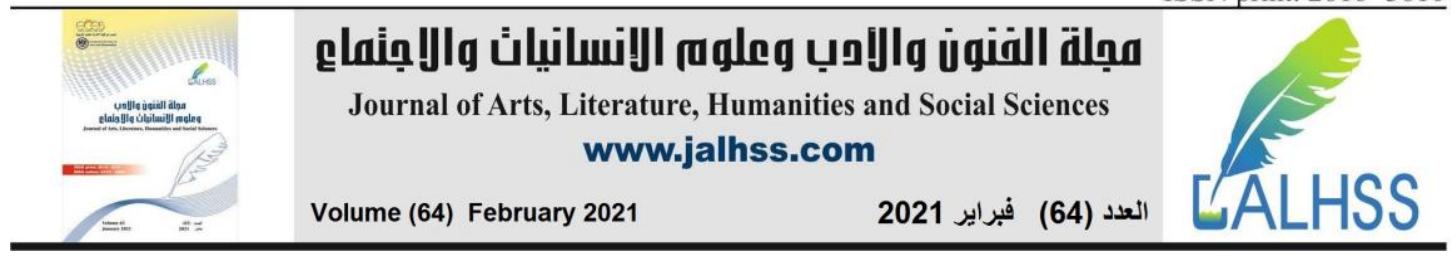

Introduction:

This era is characterized by the openness of all spheres to each other, and from these fields are arts, as there no boundaries that separate the arts from each other, such arts forms have merged together to form a single, integrated art painting and, this is the focus of our discussion in this study, where we will go through the combination of various art forms into interior design, which proves that art has no limits and can integrate with other fields and with different art forms, such as interior design, and this is the notion of this study.

Interior design is a form of design that can be developed and aligned with other forms of design and arts within the customary design rules and foundations. Where functional and aesthetic value is the most prominent concern of interior design, and since we are talking about functional and aesthetic value, it also does not contingent with different art forms.

Arts in their various forms can complement and not be a burden on the functional and aesthetic aspect of interior design. and this pointed out by (Mahmoud, 2011) that interior design is one form of arts that links between function and beauty, and it may be the reason why this was created as a service that approaches to mastermind the objects and elements used in everyday life, proving this by using Islamic decorations in interior design as an aesthetic art performance.

This study is going through the evolution of plastic art in their various forms (sculpture, painting, ceramics, ornaments) implemented in interior design in line with the basic values of interior design.

\section{Problem of this Study}

(Mohammad, 2017) noted in his study the mechanism for analyzing Islamic decorative elements and add them into interior design and furniture and he pointed out through his study (Mahmoud, 2011) on the possibility of using the heritage ArabIslamic arts in interior design. as Salama examined the intellectual dimensions of Islamic Art Which is represented by Islamic decoration (Salama, 2016) by showing Models of contemporary applications of useful products as an attempts to revive this magnificent heritage and benefited of its elements functionally and aesthetically through modern innovative visions

The study of (Fahmi \& Almomani, 2017) examines the possibility to achieve design indicators that will benefit in the use of aesthetics graffiti art in contemporary interior architecture and Saadi noted in his study about the flock Art and its implications on designing walls in interior spaces of houses an away to suit the needs of their users (Saadi \& Sultan, 2020).

In a study of (Imam, 2018), he examined the most significant design values and considerations that can enrich the culture of intellectual perception through visual scenes used in interior spaces to reflect the meaning of privacy, identity, and sense of belonging. 


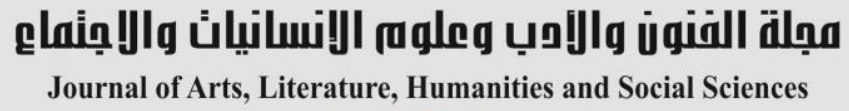

After reviewing previous studies, we have not found any studies that deals with the evolution of works of art in their various forms (sculpture, painting, ceramics, ornaments) used in interior design, therefore this study is prominent to review and discuss the evolution of the different forms of plastic arts that are used in interior design, to confirm the evolution of the plastic art elements that goes in line with interior design in case both are being associated with each other.

\section{Methodology:}

This study has followed comparative approach, to confirm the evolution of plastic art in interior design, through studying the design cases and highlighting the evolution of plastic art in interior design, to prove the evolution of plastic art elements with interior design in design cases that will be discussed in this paper, the study has compared two interior design cases one is classic and the other one is contemporary, showing the implementation of various plastic art elements, and the conclusions confirmed the assumption of this study.

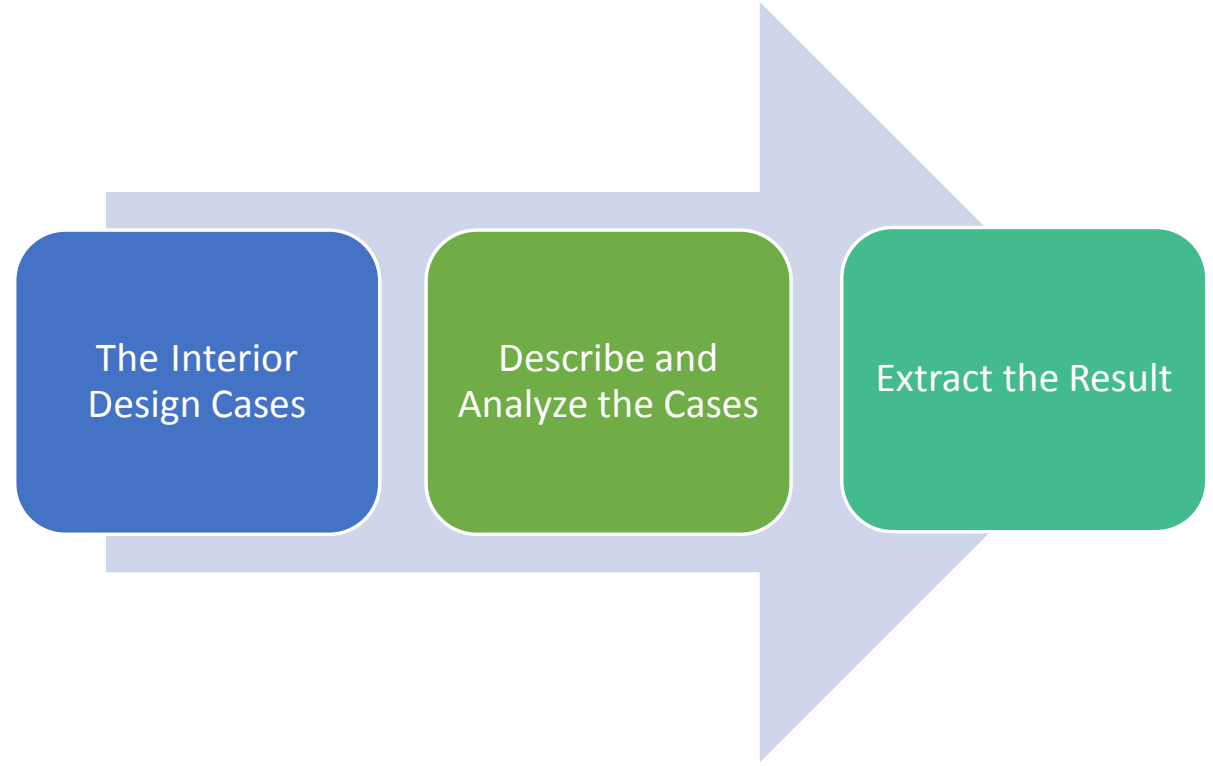

Figure 1: Comparative Research Framework. 


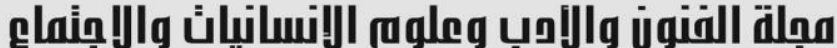

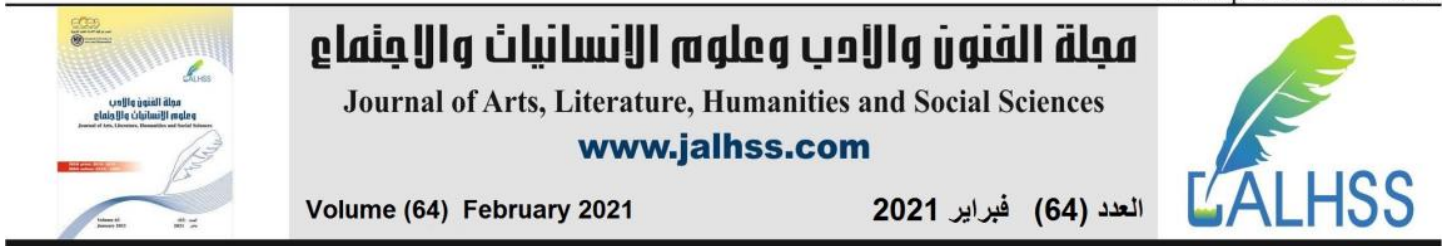

\section{Case (1)}

\section{Contemporary interior design:}

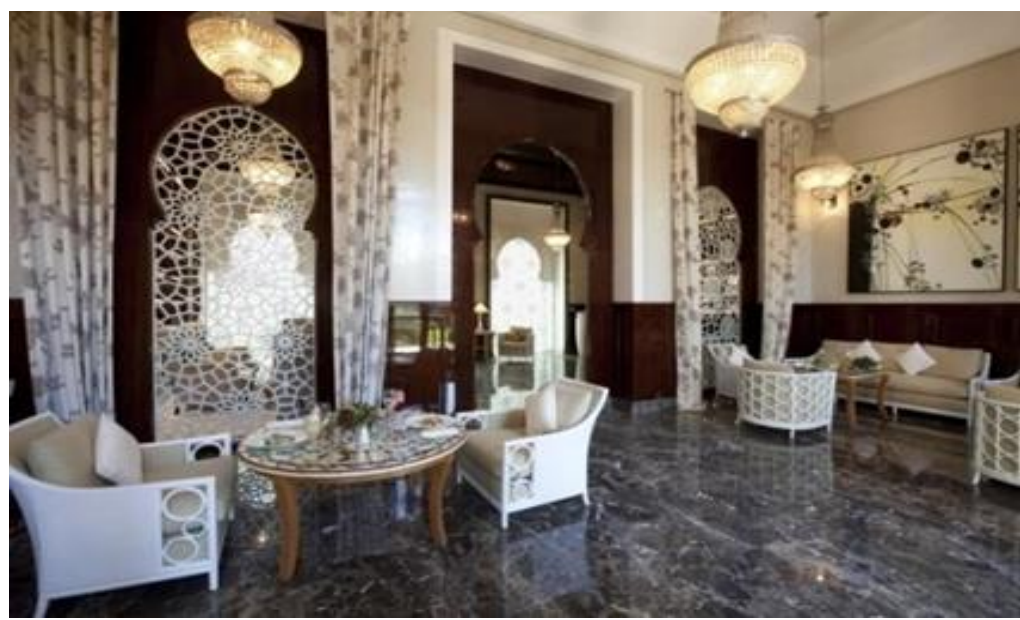

Picture (1): Geometric ornaments in the lobby of the Mansour Royal Hotel Source: www.luxurydreamhotel.com

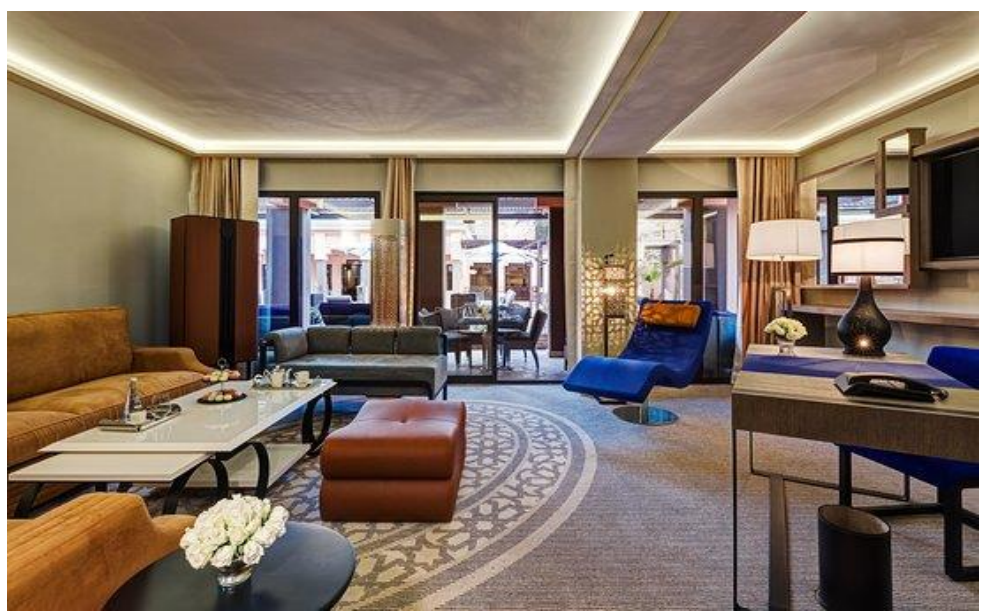

Picture (2): Geometric ornaments on the floors of the Royal Mansour Hotel Marrakech- Morocco

Source: https://www.tripadvisor.fr.

\section{Description:}

the hotel design of the entire hotel was inspired by the Islamic character, and the architecture of Islamic ornaments was dominated the general design line. As we see a whole bunch of Islamic geometric decorations in the floors and walls and in the pieces of furniture integrated into each other to make for a great design scene. 


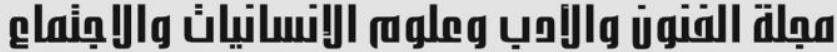 \\ Journal of Arts, Literature, Humanities and Social Sciences www.jalhss.com \\ Volume (64) February 2021 \\ العدد (64) فبراير 2021}

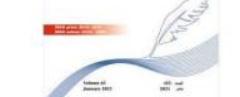

\section{Analysis:}

Islamic art has been an inspiring source for designers to draw from their intellectual theses on contemporary designs with Islamic art features and the aesthetic of Islamic ornaments. as It offers infinite solutions to contemporary designs and presents unique distinct ideas of authentic art proves this art a human-made art characterized by flexibility and fits every time and place.

This model is one of the design proposals of contemporary designers to take advantage of the aesthetics of Islamic geometry (Salama, 2016).

The space has been characterized by many Islamic geometric ornaments in walls and floors, as the contemporary design treatments for these ornaments have clearly been shown by the place and the main theme of the hotel, which is the dominancy of the Islamic characters in the place.

This brings a sense of originality and contemporary at the same time, where the designer made these ornaments in his design to present aesthetic value which is obvious in the place and corresponding the main theme of the hotel design, which is the dominancy of Islamic character with a modern touch in line with the evolution of interior design.

\section{Classic interior design:}

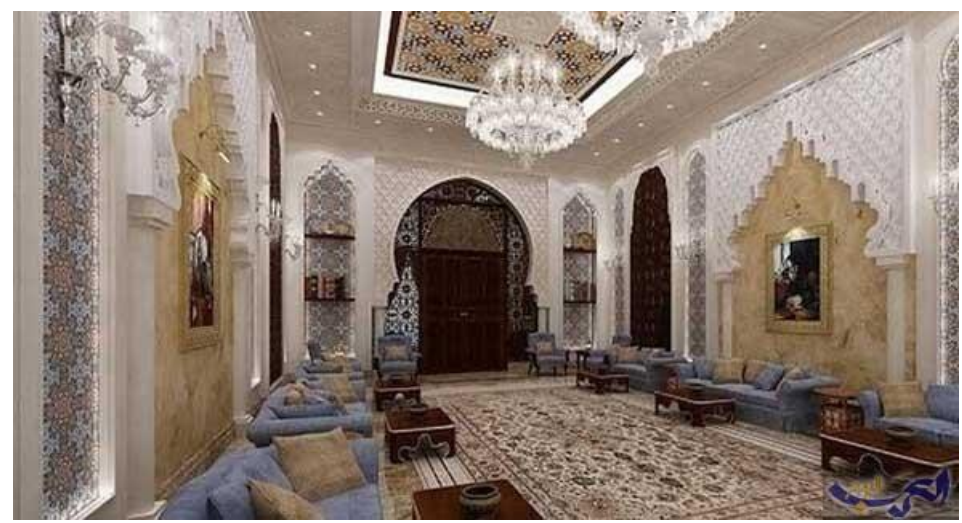

Picture (3): seating room design inspired by Classical Islamic style Source: https://www.arabstoday.net

\section{Description:}

The seat room design was inspired by the Islamic classic design, were plants and geometric ornaments are all over the place, as we see that in walls, floors, seals and in the ornaments of the windows stained with bright colors (Arabstoday, 2018). 


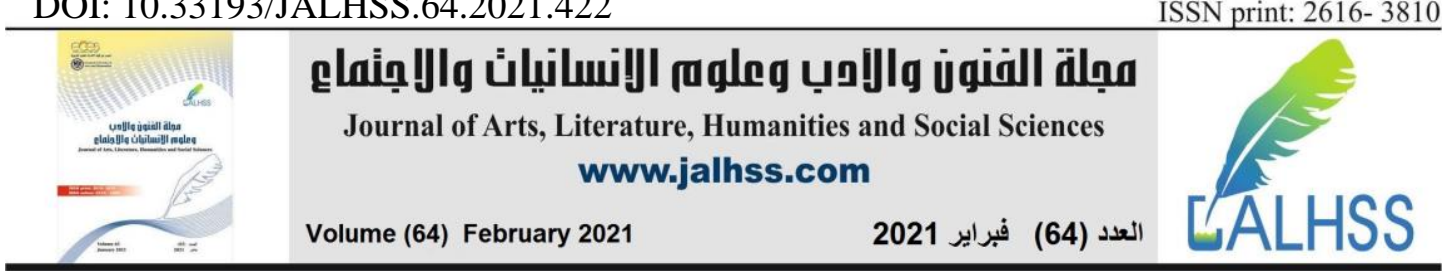

\section{Analysis:}

The Islamic art ornaments is based on warm colors like orange, much more of red color gradients, the carpets are handmade from natural dark color threads, and the stained glass with bright colors which is considered as the most prominent decoration of the Islamic art.

For accessories in the ornaments of the Islamic style, it relies on the distinctive calligraphy, which uses the drawing of the calligraphy on the vases and wall painting Copper is considered as one of the most common used metal in the Islamic ornaments style, which depends on floral and calligraphic motifs (Arabstoday, 2018).

The design in the picture (4) is a manifestation of Islamic classical design and is consisted of many floral and geometric motifs on walls, floors, ceils, and windows, as distinguished by the abundance of these decorations filled the place, on which the Islamic ornaments philosophy is based, and this is what we notice in this design, the full commitment of authentic Islamic art through the excessive use of various ornaments in the beautification of buildings.

\section{Case (2)}

\section{Contemporary interior design:}

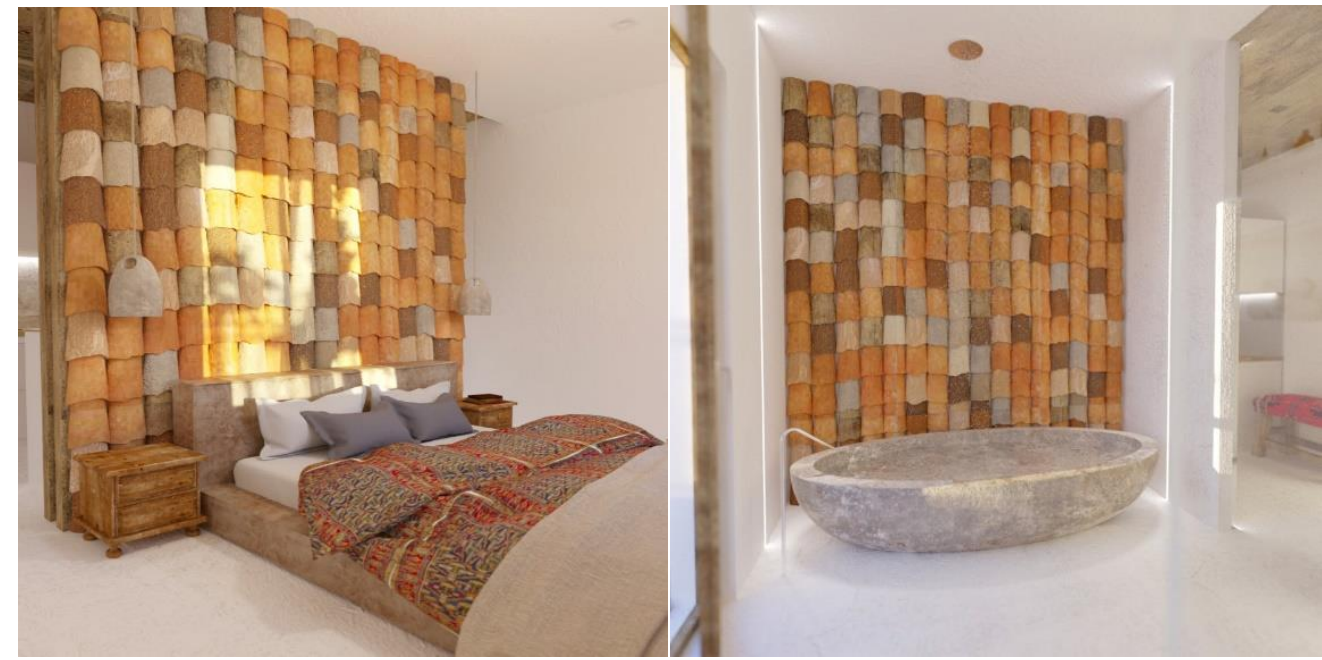

Picture (4): Hotel apartment in Bulgaria

Source: www.homeklondike.site

\section{Description:}

A hotel apartment with a ceramic mural on the bedroom wall and the bathroom, implemented using rooftop rinks, which is one of the most prevalent ceramics in Bulgaria (Homeklondike, 2017). 


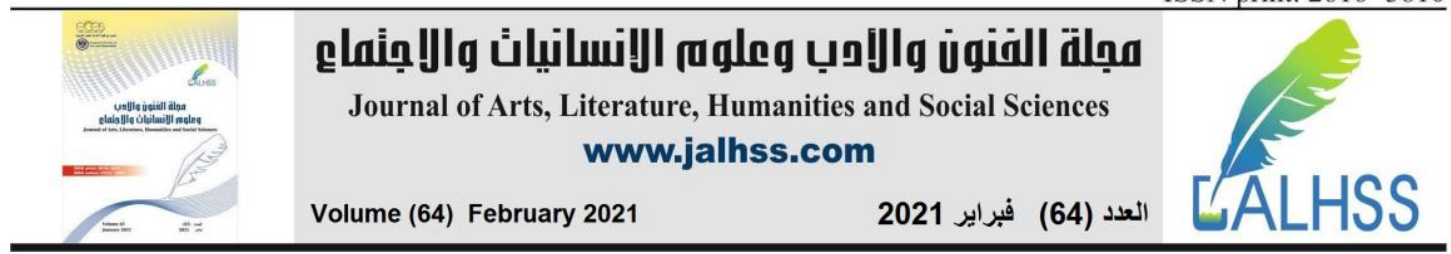

\section{Analysis:}

The design of the ceramic mural is compatible with the concepts of interior design of this hotel apartment, in which the designer expresses simplicity, and that is compatible with Bulgarian building traditions, where local colors of the same environment have been used, the walls have been lined with ceramics, which is one of the most widespread building materials in Bulgaria, and is perfectly consistent with the interior concept of the apartment (Homeklondike, 2017). and that is what we see in this simple place with its tools and colors and its design, which in practice reflects the main idea of hotel design, the integration of the use of ceramic ore with colors and the simple design in order to achieve the desired aesthetic and functional values, and to be a fundamental key element of general design.

without which there is a glitch or lack of design, which demonstrates the key role that these walls play in the general design of the space as it offers the desired aesthetic and functional values of design, and it is clearly shown the creativity in adapting ceramic material to a contemporary design that fits the spirit of the times in the different way of the traditional ceramic implementation in traditional interior design.

\section{Classic interior design:}

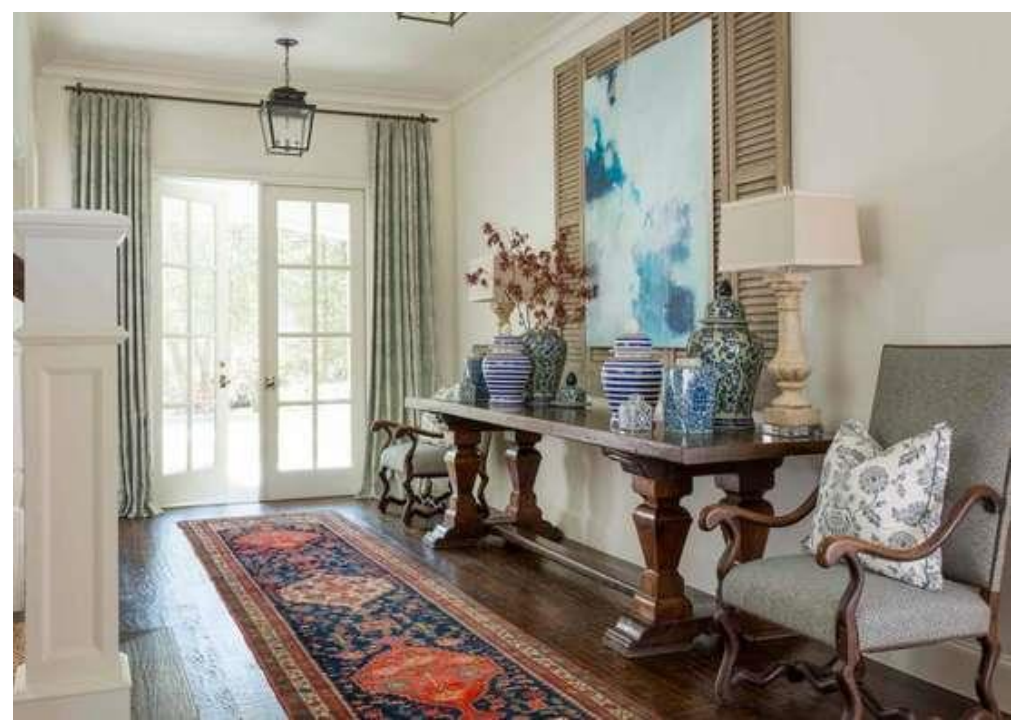

Picture (5): $19^{\text {th }}$ century designed house Source: https://www.bobvila.com

\section{Description:}

This design of the house is inspired by the 19th century, where the long curtains from the ceiling to the floor and the oriental touch of the carpet, the design shows a combination of the sense of fun and elegance by arranging the set of ceramic jars on the console table (Reddigari, 2016). 


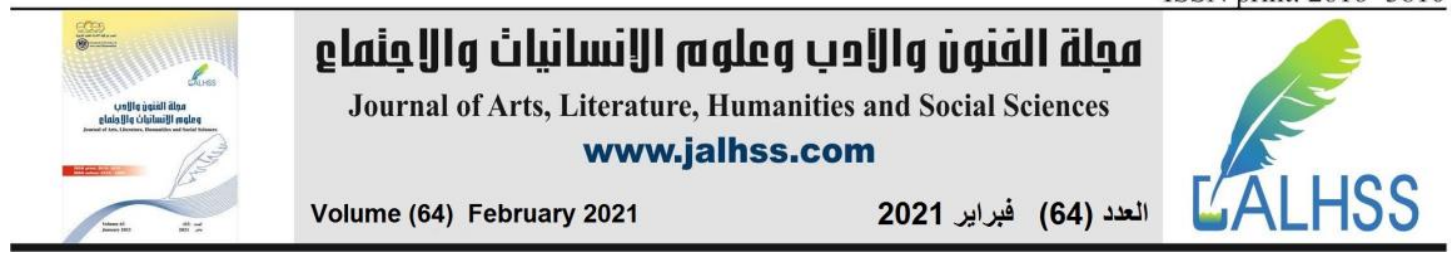

\section{Analysis:}

The design in the picture (5) is represents a 19th-century house, and the use of ceramic pieces were clearly shown in the design in line with the general style nature of the place classic design that appears through the existing furniture.

\section{Case (3)}

\section{Contemporary interior design:}

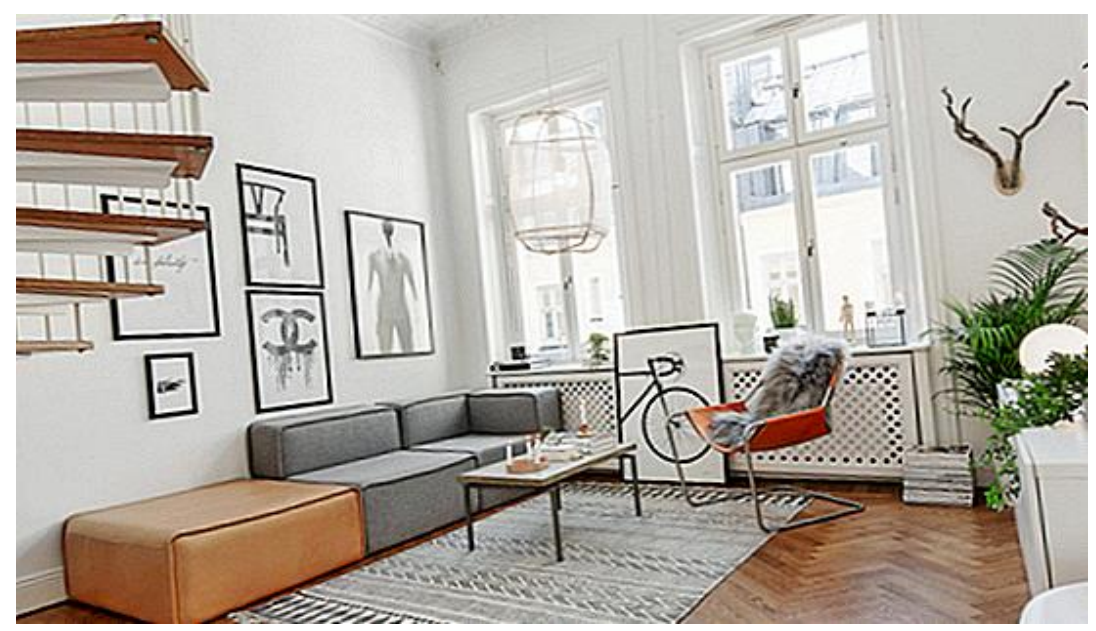

Picture (6): Scandinavian-style living room

Source: https://sy.aluzar.ru.

\section{Description:}

The Scandinavian-style designer's living room has modern furniture and horns hanging on the wall, where it considered from the most prominent elements of the Scandinavian decorations in addition to wall paintings (Aluzar, 2019b).

\section{Analysis:}

The Scandinavian style can become more "vibrant" by art pieces: Tire plates, deer horns on the wall, and wooden combinations on the control unit table (Aluzar, 2019b).

And what we actually see is that the paintings on the wall were an aesthetic value added to the design, and complementary pieces to other design elements, such as furniture, where its lines went along with the lines of the simple pieces of furniture, without being a burden on the design, but a necessary elements, to fill the vacuum that's not design-acceptable, and the painting on the wall are modern paintings that the designer chose to fit into the interior of the place, which is a modern style design . 


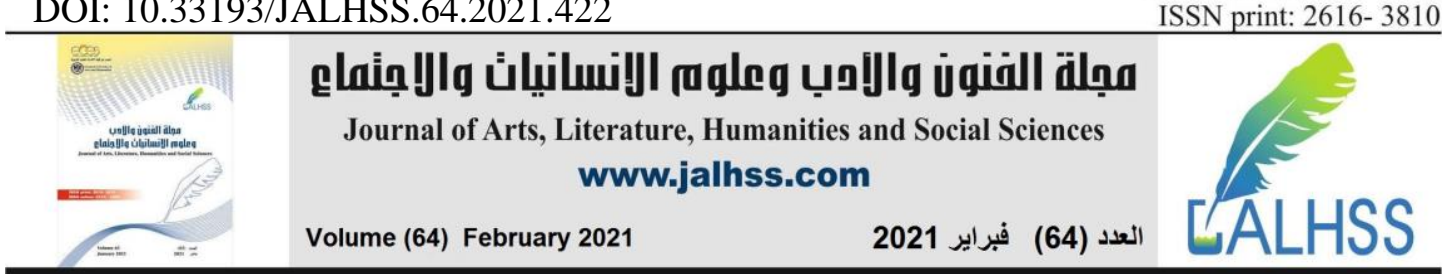

\section{Classic interior design:}

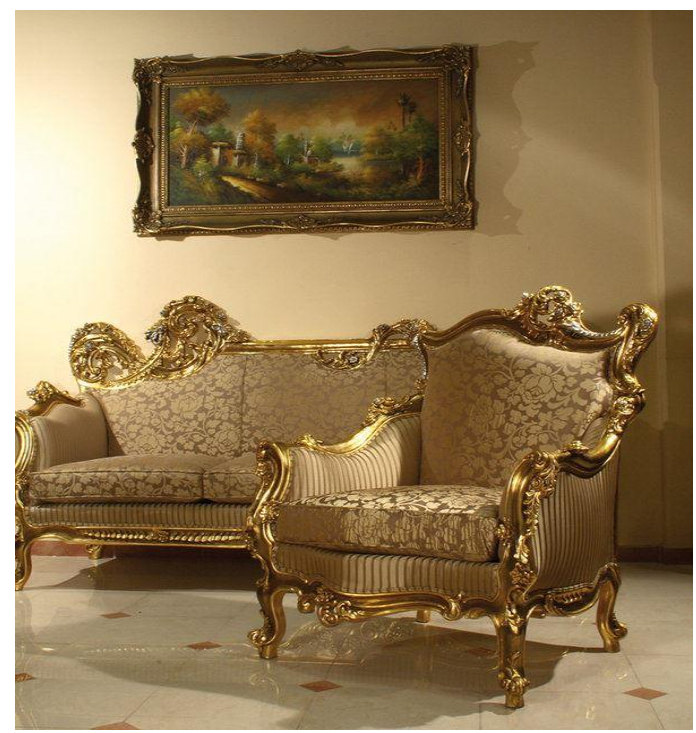

Picture (7): a quite classic Salon

\section{Description:}

Source: https://www.almrsal.com

A very fascinating classical salon, it is a traditional golden salon design with a great painting behind it, where the presence of the painting has added so much to the salon that it is considered a piece of art of beauty, elegance, and excellence (Shaima, 2016).

\section{Analysis:}

The design in picture (7) represents a classic design of a salon and the design featured the use of furniture and art paintings of a distinctive and lavish classical nature.

And that makes the place in general so unique, beautiful, elegant and so luxurious that features classic style. The use of the artboard was suitable and a complementary piece to the classical interior design and was not to decorate the space. 


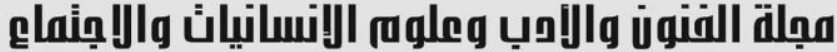

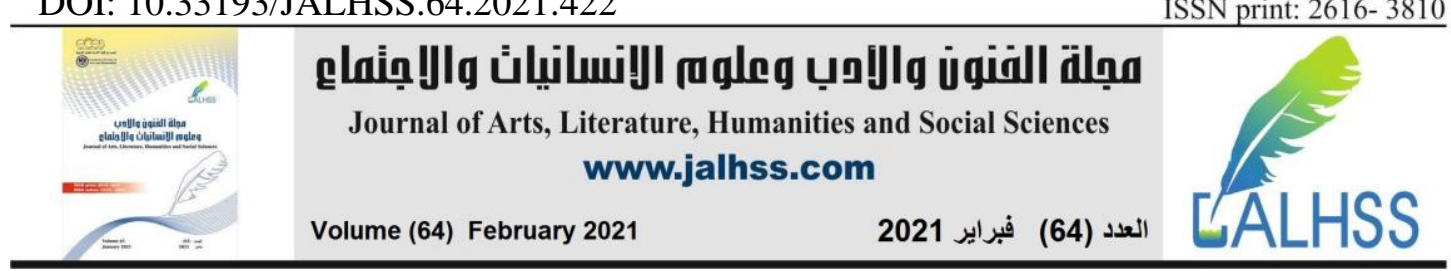

Case (4)

\section{Contemporary interior design:}

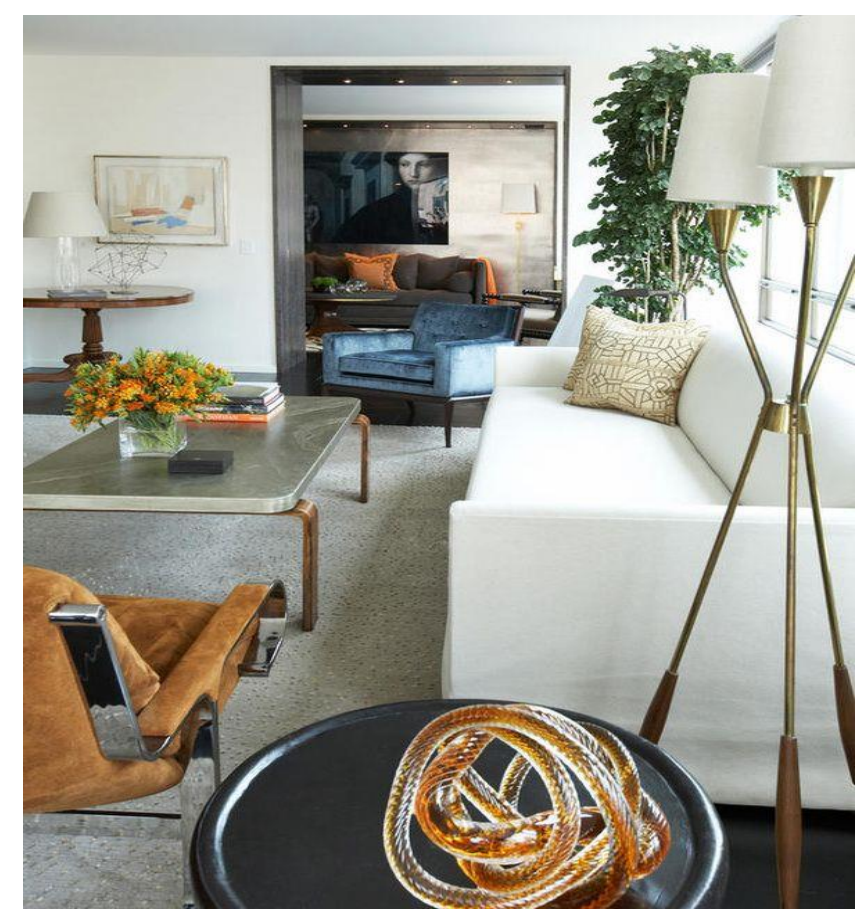

Picture (8): an apartment in Manhattan

\section{Description:}

Source: https://design-milk.com

picture (8) represents A close - up shot of an apartment in Manhattan, the apartment contains a collection of modern furniture and a collection of sculptures and paintings.

\section{Analysis:}

The design in picture (9) represents a classical design of the apartment, and it featured the use of modern furniture, art paintings, and sculptures of a modernist nature. the two sculptures appear on the tables in the apartment: Sculptures of geometric wire in the background and an interesting twisted knot in the foreground (Katz, 2014).

These sculptures are of a contemporary nature and are consistent with the general contemporary interior design. 


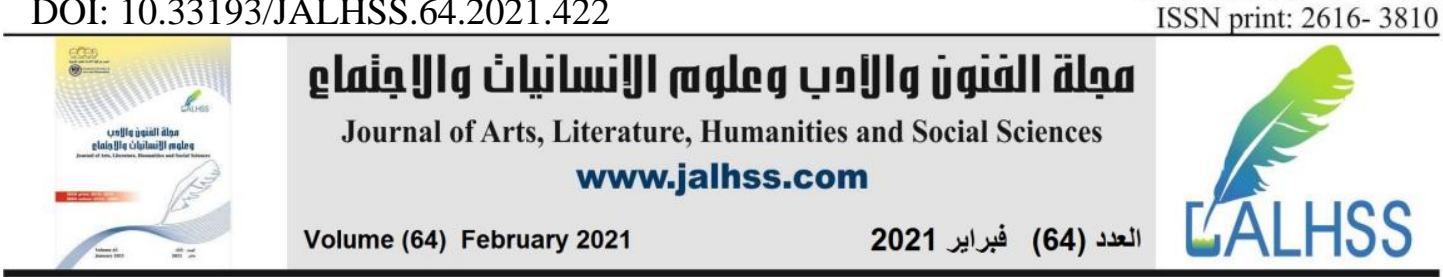

\section{Classic interior design:}

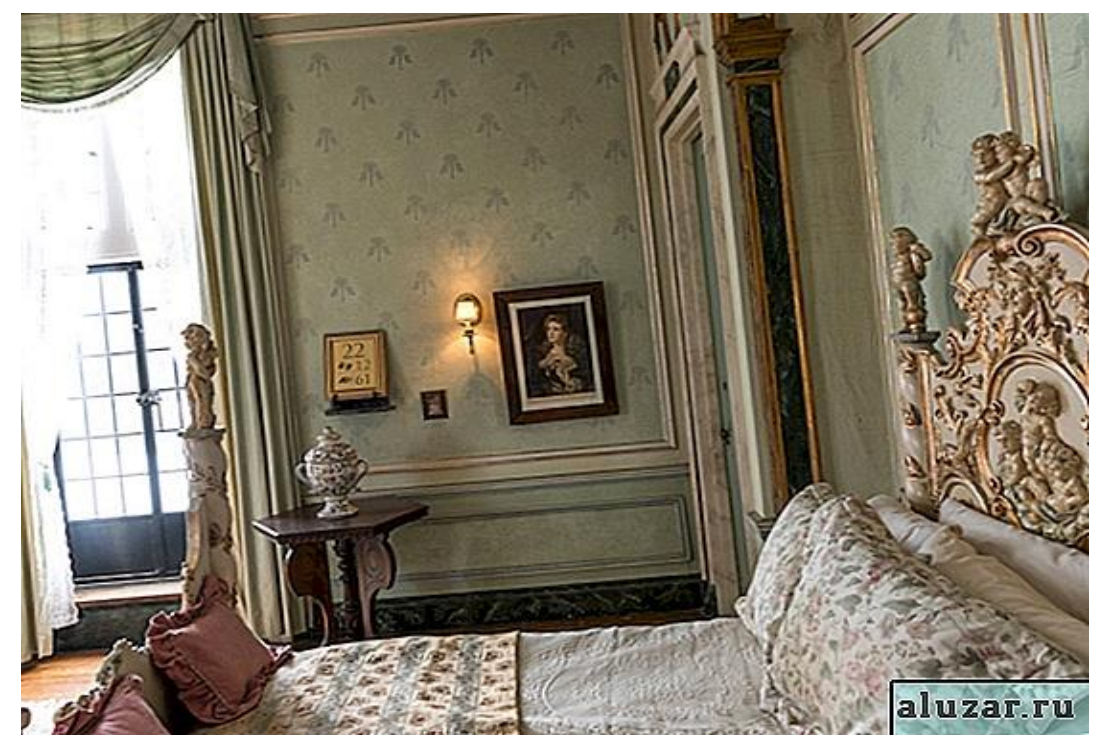

Picture (6): bedroom with classical style

Source: https://sy.aluzar.ru

\section{Description:}

A bedroom designed in the classical style, it contained various elements, such as a bed, a small table, and art pieces in the form of sculptures, a painting, and lights with marvelous and bronze colors (Aluzar, 2019a).

\section{Analysis:}

The classical furniture pieces of the bedroom are a whole set, not a separate one. The bed (middle of the bedroom), a double bed, made of expensive rare wood, with a tall, dense carved front panel with often a large umbrella, everything in the room creates a luxurious effect, reinforced by the presence of elegant sculptures, marbled or bronze elements, a combination of dark and light colors that creates an extraordinary atmosphere of comfort in the room, and the center of composition is a huge bed with some sculptures (Aluzar, 2019a).

The presence of sculptures in the room completed the classical character controlling the overall design of the room, and is one of the main design centers, if we look at the bedside, the classical sculptures and the sculptures on the front board, we understand how these elegant sculptures affects the overall design of the room, the aesthetic values, the elegance, the magnificence and the distinction that these sculptures added to the rest of the design elements.

\section{Results:}

As we have mentioned before that all forms of arts and designs are integrated with each other's in many instances and interior design is one of such forms of art that 


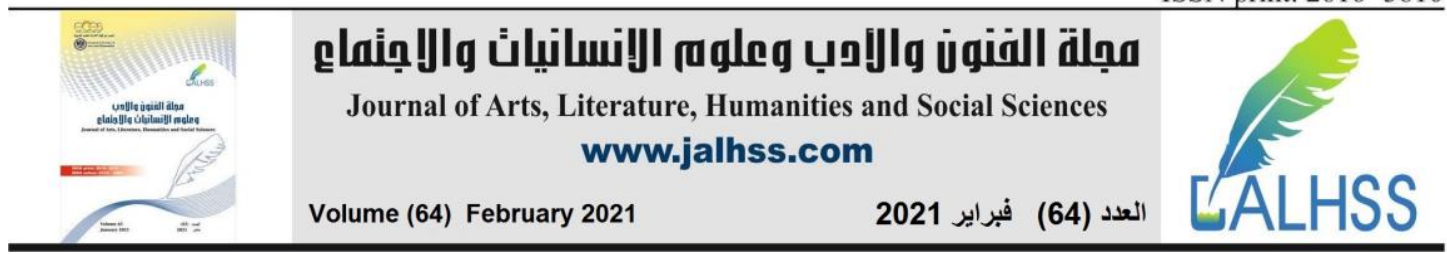

harmonizes and uses different art forms such as sculpture, painting, decoration, and ceramics in its compositions, this has made the art forms that accompany interior design evolve were its existed with the interior design.

The above-mentioned description and analysis of some design cases in this study has shown that there has been a clear and tangible evolution and change in the different forms of art (sculpture, painting, ceramics, ornaments) that exist in these design cases in line with the evolution of interior design both classical and contemporary cases. And that proved the main purpose of this study that there is a clear and natural evolution in the plastic art elements used in the interior design, which emphasizes the obvious impact of the interior design on the plastic art elements in case both have existed together.

\section{References}

1. Aluzar. (2019a). Bedrooms in classic style. Aluzar. Retrieved January 24, 2021, from https://sy.aluzar.ru/1027-classic-style-bedrooms-75-photos-luxury-shineand-co.html.

2. Aluzar. (2019b). Art objects inside. Aluzar. Retrieved January 24, 2021, from https://sy.aluzar.ru/2390-art-objects-in-the-interior-how-to-use-the-full-pow e.html.

3. Arabstoday. (2018, March 17). Islamic style dominates the decoration designs of many Arab countries. Retrieved January 24, 2021, from https://www.arabstoday.net.

4. Katz, M. (2014, May 12). 12 Rooms that Showcase Sculpture. Retrieved January 24, 2021, from https://design-milk.com/12-rooms-that-showcase-sculpture/.

5. Fahmi, M., \& Almomani, W. (2017). The Aesthetics of Graffiti Art in the Contemporary Interior Space. Jordanian Journal of Arts, 10(1), 35-48. Retrieved January 18, 2021, from http://journals .yu.edu.jo/jja/ JJAIssues/ Vol10Nom 12017 /Nom3.pdf.

6. Homeklondike. (2017, July 28). Close-to-Nature Holiday Residence in Sunny Bulgaria. Retrieved January 18, 2021, from http://homeklondike.site /2017/07/2 8/close-to-nature-holiday-residence-in-sunny-bulgaria/.

7. Imam, A. (2018). Visual arts and a culture of meaning in interior design. In The Fourth International Conference on Plastic Arts and Community Service. Luxor: South Valley University. 


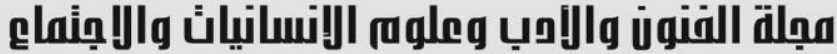 \\ Journal of Arts, Literature, Humanities and Social Sciences www.jalhss.com

8. Mahmoud, S. A. (2011). Decorative Elements in the Interior Design of the AlMustansiriya School: An Analytical Descriptive Study (Unpublished master's thesis). The World Islamic Sciences University. doi:https://ia801006.us.archive.org/12/items/ktp2019-tra7786/ktp2019-tra 778 6.pdf.

9. Mohammad, S. I. (2017). Interior Design and Furniture through a Contemporary Vision of Geometrical Analysis of Islamic Ornamental Units. International Design Journal, 1, 1-31. Retrieved from https://www.faa-design.com/conf/pdf/conf4/4 .pdf.

10. Reddigari, M. (2016, November 03). 18 Inviting Entryways We Love. Retrieved January 24, 2021, from https://www.bobvila.com/slideshow/18-invitingentryways-we-love-50625.

11. Saadi, H. F., \& Sultan, K. A. (2020). Pop Art and Their Reflection on Walls Design in the Interior Spaces. Journal of Arts, Literature, Humanities and Social Science, 52, 279-301. Retrieved January 18, 2021, from http://www.jalhss.com/index.php/ jalhss/article/view/90/83.

12. Salama, H. M. (2016). Aesthetics geometric shape in Islamic arts and its modern applications. Architecture and Arts Journal, 3, 1-15. Retrieved January 18, 2021, from https://mjaf.journals.ekb.eg /article_20516_5421bd218e $7375635150 f 45 f$ 16ae6ed6.pdf.

13. Shaima, M. (2016, October 30). The latest decorations for salons 2017. Retrieved January 24, 2021, from https://www.almrsal.com/post/395475. 